\title{
Academic Mobility as a Factor of Improving the Competitiveness of University Graduates
}

\author{
${ }^{1}$ S.G. Absalyamova, ${ }^{2}$ R.L Sakhapov, ${ }^{3}$ T.B. Absalyamov, ${ }^{4}$ C.F. Mukhametgalieva \\ 1,3,4 Kazan Federal University, ${ }^{2}$ Kazan State University of Architecture and Engineering \\ E-mail: s.absalyamova@yandex.ru, Contact: +7-917-234-7081
}

\section{Received: 15th December 2017, Accepted: 20th December 2017, Published: 31st December 2017}

\begin{abstract}
The article investigates the influence of academic mobility on the quality of the university graduates training. We have identified the current trends of development of academic mobility of students in higher education system in Russia. We have investigated the motives of participation in academic mobility, subjective and objective factors in a partner-university choosing. We have presented the content of academic mobility in the paper from the perspective of four approaches: functional, personal, cultural and virtual. Particular attention is paid to the virtual mobility, virtual learning environment. We have made an analysis of the positive aspects and problems of the organization of virtual mobility. Much of the research is devoted to the study of virtual mobility's impact on improving of the quality of education and competitiveness of graduates. The article summarizes the experience of Russian students in virtual mobility. The basic mechanisms for further development of the partnership of Russian and European universities have been offered in the paper.
\end{abstract}

Keywords: Academic Mobility, International Educational Integration, Virtual Mobility, Virtual Learning Environment, Competitiveness.

\section{Introduction}

A great attention is paid to academic mobility of students and university teachers in the framework of the Bologna process. The main objective of mobility is to give the student the opportunity to get a broad education in the chosen field of study, to provide an access to widely recognized centers of knowledge, where the traditional leading scientific schools were formed, to expand the knowledge of the student in all areas of the world culture. [1] According to forecasts, $20 \%$ of university graduates from the Bologna Process countries will go through a period of study or research abroad by 2020 .

Scientist from different countries have worked on the question of impact of academic mobility on quality of education $[2,3,4]$. Their articles reflect the universal characteristics of participation in academic mobility. To conduct the study, we have developed our own methodology and applied it to the research of dependence between academic mobility and the competitiveness of a number of high school graduates in Russia. The study used the method of expert evaluations. Both experts and students were asked to assess the impact of academic mobility on the competitiveness of university graduates.

In recent years, Russia has paid great attention to academic exchange of students and professors. It has happened due to the fact that academic mobility is one of the most important factors of the process of integration of Russian universities in the international educational space.

As a result:

- Students have the flexibility to choose an individual educational trajectory, better educational services;

- The new conditions of competition and cooperation are being formed for universities;

- The prospects of scientific and educational cooperation are opened for scientists and teachers;

- The labor market becomes international, that facilitates the employment of qualified personnel.

The content of academic mobility may be presented from the perspective of four approaches: functional (academic mobility of students as a set of functions of the person); personal (academic student mobility as a tool for the development of personal qualities); cultural (academic student mobility as a tool for cultural and intellectual exchange); virtual (academic mobility of students within the possibilities of distance education).

The main criteria of efficiency of the organization of academic mobility of students are:

- The number of foreign students (incoming mobility);

- The number of national mobile students (outgoing mobility);

- The percentage of foreign graduates (bachelors, masters);

- Focused coverage of academic mobility in all spheres of education (humanitarian, technical, natural sciences, medical);

- The index of affordability of academic mobility on social backgrounds;

- The availability of academic mobility in view of the volume and sources of financing;

- The use of English as the lingua franca;

- Employment of mobile students.

There were identified the tendencies of the development of academic mobility of students:

1) The increase of students' flows between countries as a result of education globalization, which has necessitated the creation of an international system of licensing, certification and accreditation, designed to provide high quality vocational training; 
2) The emergence of transnational education, realized through the creation of cross-border higher education institutions with the issuance of double diplomas, offshore campuses, franchising of training programs, development of distance learning and the organization of academic mobility of teachers and students;

3) Europeanization of higher education in the countries - participants of the Bologna Process and student access to the European programs of academic mobility as a result of the inclusion of Russian universities into the European educational space;

4) The improvement of the quality of educational process in higher educational institutions in Finland, focused on education and training of mobile students who are able to operate in a quickly changing international environment;

5) Multilingualism and intercultural education, the improvement of the language training of students, allowing them to explore the culture of the host country and to communicate using a foreign language during the course of participation in foreign academic mobility programs;

6) The changes in the nature of teaching, learning and creation of flexible educational programs for the implementation of academic mobility of students.

Academic mobility in the Russian context means cooperation not only with foreign universities, but also with Russian. In this case, we can talk about the external and internal mobility [5]. The external (international) academic mobility means the training of students in foreign universities, as well as the work of teachers in foreign educational or scientific institutions. The internal (domestic) academic mobility means the training of undergraduate and graduate students, as well as the work of teachers and university staff in the leading Russian universities and research centers.

\section{The Experience of Russian Higher Education Institutions in Academic Mobility}

The study of the problem of student participation in academic mobility was carried out by the example of Kazan (Volga Region) Federal University and KSUAE. Today the University is actively involved in the programs of academic mobility, developing both domestic and international mobility. The participation in internal mobility is built on the concept of a network of education [6].

After the survey among the students, we can say that the main motives of participation in academic mobility are: the improvement of professional knowledge $(74 \%)$, the improvement of the competitiveness on labour market $(70 \%)$, the improvement of foreign language skills $(45 \%)$, the acquaintance with the host country culture $(35 \%)$, the acquaintance with the international education system $(28 \%)$, the next level of education $(20 \%)$, getting new friends (15\%), finding a job abroad $(8 \%)$.

Studying the experience of participation in foreign academic mobility made it possible to determine the factors that influence on the choice of a foreign university.

Modern information and communication technologies, the provision of most university teachers and students by means of communications create conditions for the organization of virtual mobility. Bologna documents say that "virtual mobility is not a substitute for physical mobility" [1].

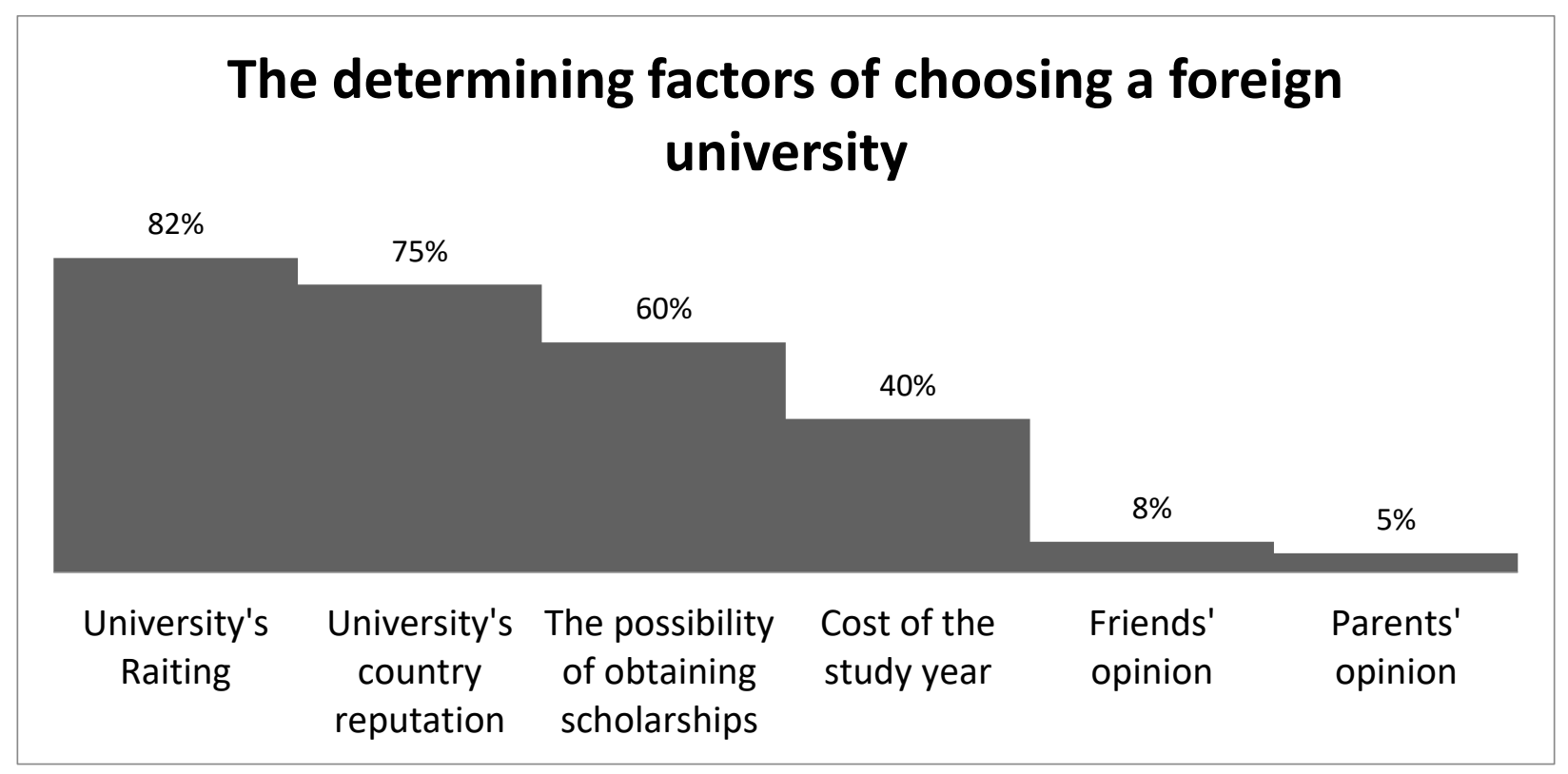

Figure 1. The Determining Factors of Choosing a Foreign University 
However, studies have shown that the greatest effect of participation in academic mobility is achieved by combining the use of physical mobility and elements of virtual learning.

The main advantages of virtual education are:

1. The individualization of education process.

2. Massiveness, there is no limit on the number of participants in training.

3. Absence of the need for physical movement, of binding to place and time.

4. High degree of students training flexibility: the opportunity to build individual educational trajectories, the total set of credits with a choice of courses of different universities.

5. The ability to pre-testing, testing of selected high school curriculum.

6. The ability to continue their education after completing the program of academic mobility.

The disadvantages of virtual mobility are in the impossibility of full immersion into the educational process of other universities, because the primary place of studying is student's own university. Difficulties arise during the work on different information platforms that implement distance learning. Also, there are inconsistencies of organization models of educational process in participant-universities and difference in the estimation of the role of the teacher, tutor or curator of the educational process, the necessary degree of interactivity, etc.

Today we can speak about significant empirical experience in the use of remote technologies in the academic mobility [7].

Active use of these technologies is caused by the following factors:

- Information is available through a standard web browser;

- All the tools and interfaces as simple and understandable.

The most interesting solutions in the virtual mobility are Adobe Acrobat Connect and Open meetings. IT systems provide the following areas of eLearning: virtual Classrooms; on-line training; the performance improvement system based on LMS. Recognition of the possibility of virtual mobility is supported by various international projects, which are actively involved in the Russian high schools
[8,9]. Along with the classic e-learning tools there are some recent tools:

- Creation of special websites about the basic educational resources and mobility programs, the introduction in educational institutions of the special chat-rooms for the organizers of the mobility of students, teachers, etc., to discuss and exchange information;

- E-voting system, designed to create interactive lectures, increase the participation of students in the discussion of the proposed issue or point of view;

- Peer review system and technology of collective creation and editing (wiki);

- Asynchronous communication tools (forums and blogs);

- Social bookmarking and social networking;

- Podcasting and online lectures, video streaming etc.

All of these technologies are the components of an open virtual platform based on Web 2.0, that allow you to organize an effective online collective and individual work and integrate seamlessly into the virtual learning environment, providing the academic mobility of both students and teachers.

\section{Analysis of The Impact of Participation in Academic Mobility Programs on Quality of Education}

The research of the influence of the integration processes in education has shown their positive impact on the current progress of students, their professional competence and overall quality of training of future specialists. All of this greatly increases the academic mobility, employability and career success.

Thus, the study of students' progress during academic mobility has shown a significant advantage to students, who studied before the cooperation.

It is clearly shown in the graph, where a red line is the progress of students with active participation in the integration processes, and blue line is the progress of students before the start of mobility programs. The Y axis shows the average scores for all semesters in all subjects. 


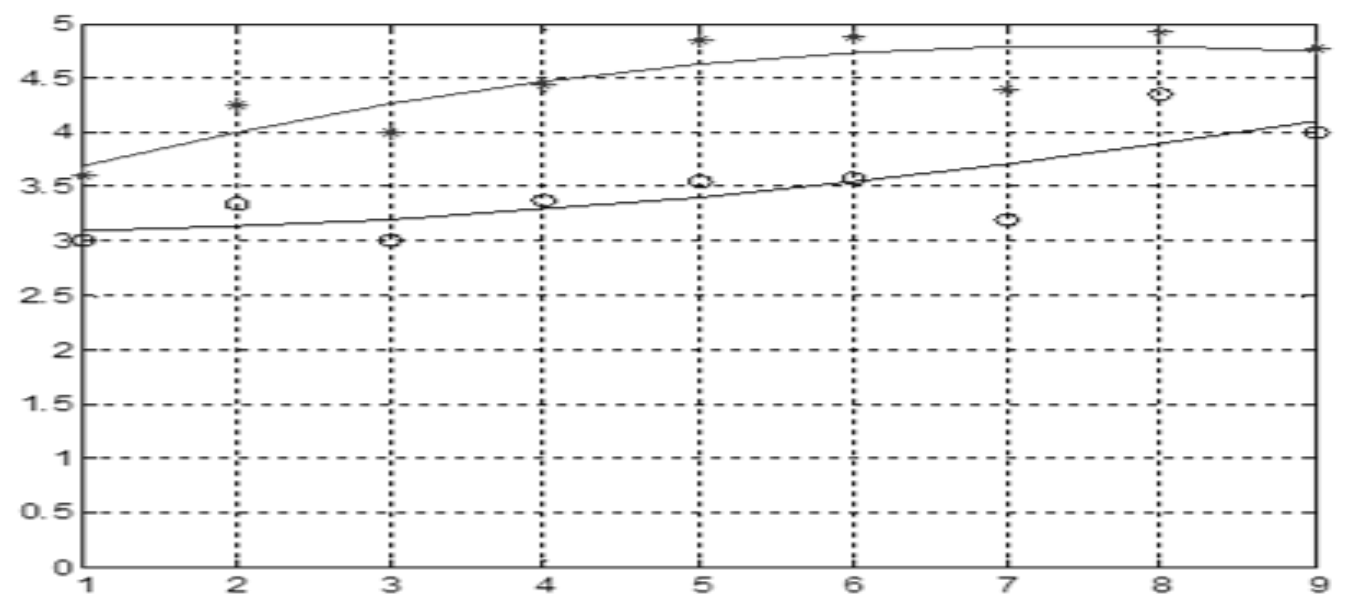

Figure 2. Student Performance Before and After Academic Mobility Programs (The Higher Line is for "after", and the Lower is for "before").

$\mathrm{Y} 1=-0.0259 \cdot \mathrm{X} 2+0.3914 \cdot \mathrm{X}+3.3196 ;$ - students' performance after the participation in academic mobility;

$\mathrm{Y} 2=0.0121 \cdot \mathrm{X} 2+0.0054 \cdot \mathrm{X}+3.0764 ;$ - students' performance before the participation in academic mobility.

The study of academic mobility of graduates was conducted by questionnaire. All graduates responded positively to the question: "Did the participation of the university in academic mobility programs has an impact on your career growth?" They noted that the participation in academic mobility has allowed them to form an idea of the advanced achievements in this area and now they are always eager to get close to this level in their academic activities. In addition, acquaintance with foreign cultures in the period of study in university changed their attitudes to learning, motivation system, which has a positive impact on their professional competence and created a foundation for future career growth.

\section{Students' evaluation of the impact of academic mobility on their competitiveness}

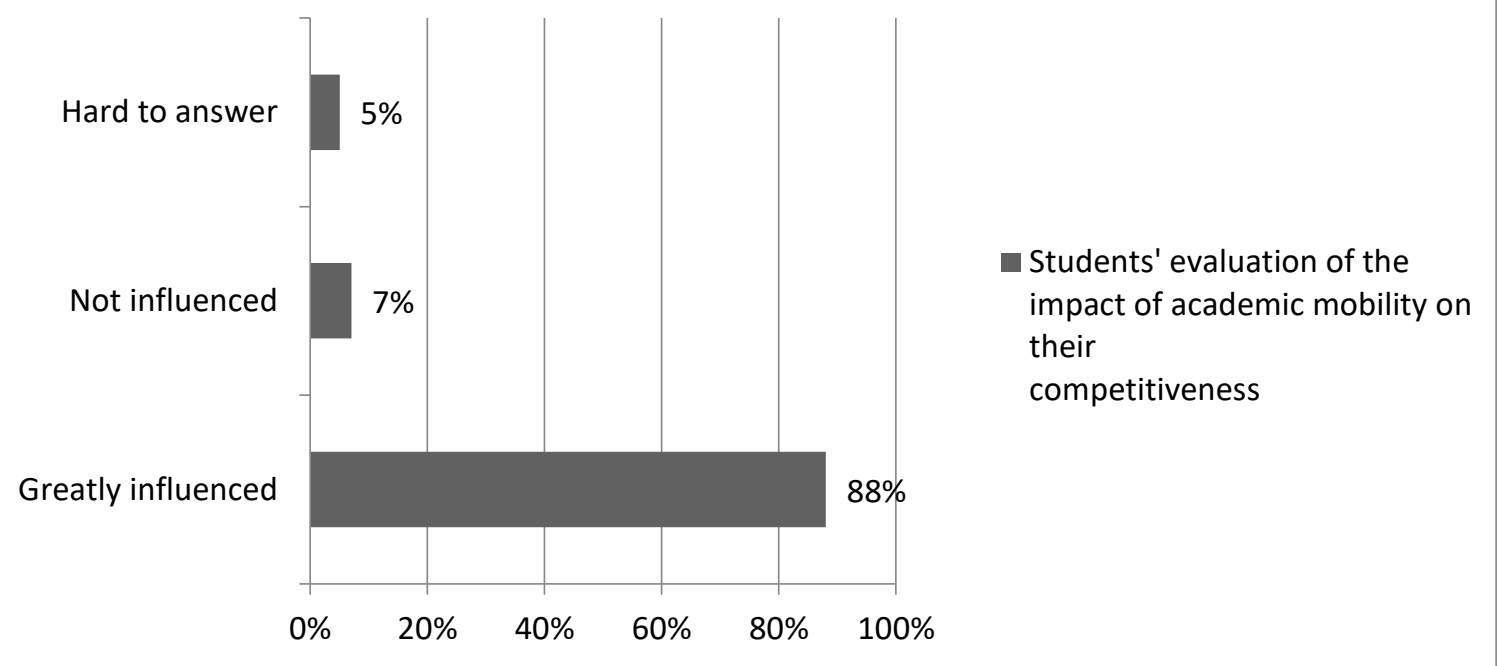

Figure 3. Students' Evaluation of the Impact of Academic Mobility on their Competitiveness

The participation in academic mobility, including virtual, is an excellent way to professional and personal adaptation, which ultimately gives the students the resource of freedom. First, the opportunities for graduates of such programs for the subsequent selection of their educational trajectory at any university in the world are expanding. Every year about $30 \%$ of our high school graduates enter graduate programs in the leading universities of the world. Second, the graduates begin to feel much more confident in their abilities and capabilities. 
Studies show that the participants of academic mobility got a real advantage over other graduates. They: have experience in cross-cultural communication; perfectly adapt to a foreign environment; assimilate elements of the work ethic adopted by Western companies; start to be fluent in several foreign languages; know how to present themselves; feel confident in any situation.

Third, for these graduates the employment ceases to be a problem, and they are becoming popular in the Russian organizations and international companies.

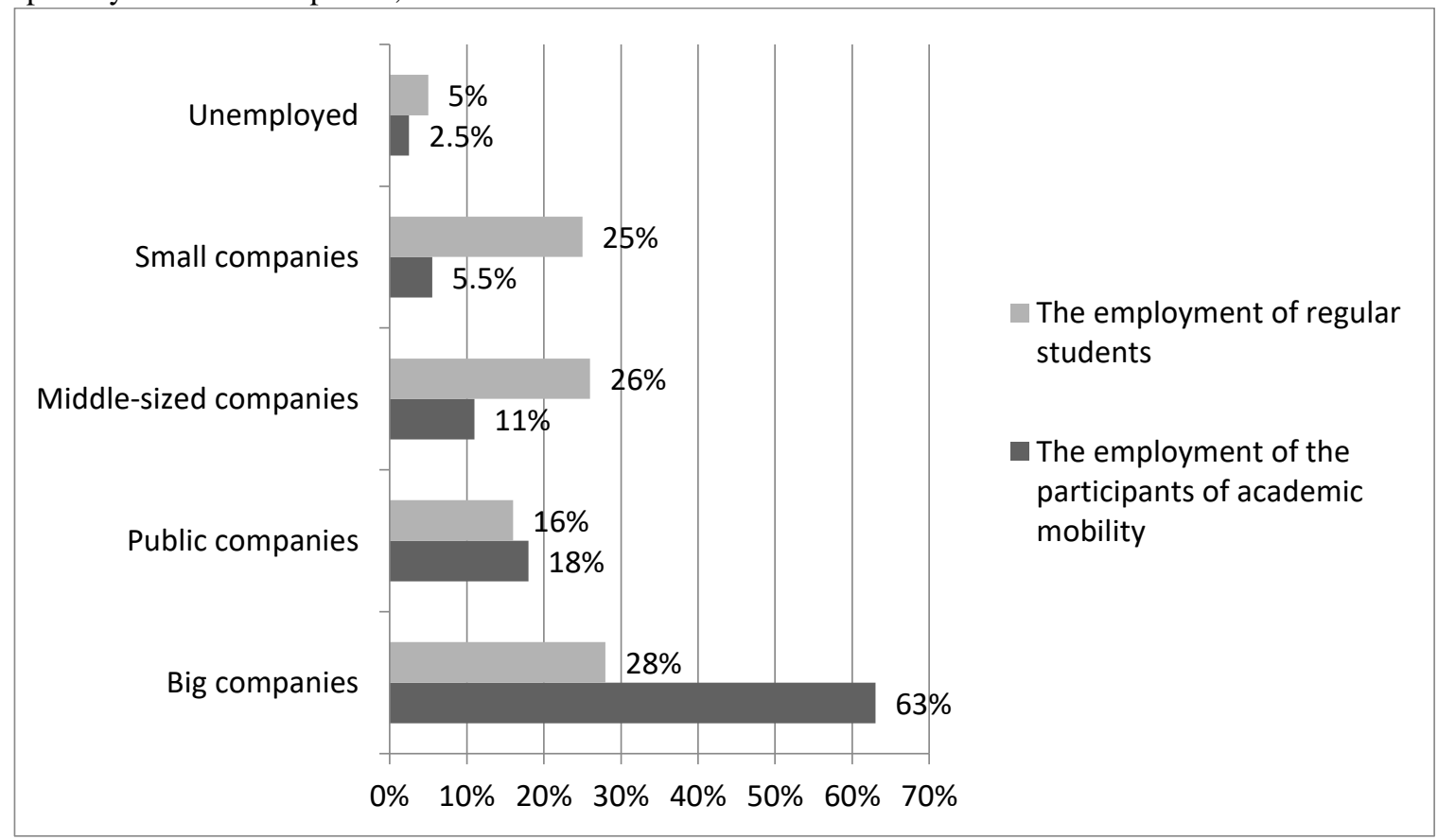

Figure 4. The Employment of Regular and Mobile Students

Studies have shown that participation in virtual mobility has a great influence on the development of flexible forms of employment. It allows graduates to quickly adapt to various types of remote employment and use it to increase revenue [10]. This becomes especially important in the process of integrating the Russian economy into the global economy [11]. Students received the skills of independent development of various kinds of professional knowledge, which contributed to their professional mobility in the labor market.

\section{Conclusion}

Thus, our analysis shows that academic mobility can be seen as a mean of development, innovation and internationalization of the educational process. Virtual mobility is being increasingly developed. It provides access to international education resources at the lowest cost. Results of the study show the growing influence of academic mobility to increase the competitiveness of university graduates. It allows to form a specialist, who meets the best world education standards. Despite the emerging challenges we need to look for and develop various forms of the academic mobility for students and teachers.

\section{Acknowledgements}

The work is performed according to the Russian Government Program of Competitive Growth of Kazan Federal University.

\section{References}

1. The Bologna Declaration of 19 June 1999 // Berlin-Bologna-Web-Page.

http://www.bologna-

berlin2003.de/pdf/bologna_declaration.pdf

2.Vázquez, L.K., Mesa, F.R., López, D.A. To the ends of the earth: Student mobility in southern Chile// International Journal of Educational Management. Vol. 28, 2014, pp. 82-95.

3. Dall Alba, G., Sidhu, R. Australian undergraduate students on the move: experiencing outbound mobility //Studies in Higher Education. Vol. 40, 21 April 2015, pp. 721-744.

4.Filipe, P.P., Ferreira, J.C. A student personal system for bologna process mobility// KMIS 2009 1st International Conference on Knowledge Management and Information Sharing, Proceedings 2009, pp. 194-199.

5. Gubaidullina, T.N. Systemic approach in the study of problems of territories' sustainable 
ecological and economic development//Mediterranean Journal of Social Sciences. Vol. 6, Issue 1S3, 2015, pp.232-236.

6. Sakhapov, R.L., Absalyamova, S.G. The use of telecommunication technologies in education network//Proceedings of 2015 12th International Conference on Remote Engineering and Virtual Instrumentation, REV 2015, p.14-17.

7. Apple, M. W. Globalizing Education: Policies, Pedagogies and Politics / M. W. Apple, J. Kenway, M. Singh. New York: Peter Lang, 2005. - 311 p.

8. Byram, M. Students, Staff and Academic Mobility in Higher Education / M. Byram, F. Dervin. Cambridge: Cambridge Scholars Publishing, 2008. - 320 p.
9. Loveland, E. Student Mobility in the European Union / E. Loveland // International Educator.Vol. 17,2008 , pp. 22-25.

10. Absalyamova, S.G., Absalyamov, T.B. Remote employment as a form of labor mobility of today's youth//Mediterranean Journal of Social Sciences. Vol. 6, Issue 1S3, 2015, pp. 227-231.

11. Gallyamova, D.K., Toumashev, A.R., Malaev, V.V. Influence of globalization on development of the Russian economy // Mediterranean Journal of Social Sciences. Vol. 5 (18 SPEC. ISSUE), 2014, pp. 133-138. 